\title{
Elderly women who received Helicobacter pylori- eradicating therapy have reduced risk of low skeletal muscle mass
}

\author{
Myong Ki Baeg \\ Myung-Gyu Choi \\ Sun-Hye Ko \\ Chul-Hyun Lim \\ Jin Su Kim \\ Yu Kyung Cho \\ Jae Myung Park \\ Young-Seok Cho \\ Bo-In Lee \\ In-Seok Lee
}

Department of Internal Medicine, The Catholic University of Korea College of Medicine, Seoul,

Republic of Korea

This article was published in the following Dove Press journal:

Clinical Interventions in Aging

30 October 2015

Number of times this article has been viewed

Background: Sarcopenia is associated with adverse outcomes such as physical disability, poorer quality of life, and death. Helicobacter pylori (HP) eradication increases ghrelin secretion, which may be a possible treatment for sarcopenia. We investigated whether HP eradication reduces the risk of low muscle mass (LMM), which is an integral component of sarcopenia.

Materials and methods: Healthy, asymptomatic women aged $\geq 60$ years who participated in a health screening program were enrolled. Subjects with a history of HP eradication were compared with those who were $\mathrm{HP} \mathrm{IgG}^{+}$, but had not received HP-eradicating therapy. Body composition was measured by multifrequency bioelectrical impedance analysis. LMM was defined as body muscle mass 2 standard deviations below the mean muscle mass of healthy women aged 20-39 years from the same program. Multivariable analysis was used to identify sarcopenia risk factors.

Results: Three hundred seventy-two women had received HP eradication, while $689 \mathrm{HP} \mathrm{IgG}^{+}$ women had not. The prevalence of LMM was significantly lower in those who received HP eradication ( $13.7 \%$ vs $21.6 \%, P=0.002)$. Multivariable analysis identified risk factors for LMM as age, white blood cell count, serum total protein concentration, and the metabolic syndrome. HP eradication (odds ratio: $0.632,95 \%$ confidence interval: $0.440-0.824, P=0.013$ ) was a significant preventive factor, and exercise (odds ratio: 0.710, 95\% confidence interval: 0.504-1.002, $P=0.051$ ) had a preventive tendency.

Conclusion: HP eradication might reduce LMM risk. This finding should be confirmed in prospective longitudinal studies to determine the long-term effects of HP eradication on sarcopenia.

Keywords: sarcopenia, Helicobacter pylori, eradication, bioelectrical impedance analysis

\section{Introduction}

Sarcopenia, which means "loss of flesh", is used to describe the progressive, agerelated decline in skeletal muscle mass and function. ${ }^{1}$ Sarcopenia has important clinical implications because it is associated with adverse outcomes such as physical disability, impaired cardiopulmonary function, unfavorable metabolic effects, falls, poorer quality of life, and death. Sarcopenia can arise from many causes such as physical inactivity, multimorbidity, smoking, insulin resistance, changing endocrine function, and nutritional deficiencies..$^{2-4}$ Although treatments such as testosterone, ghrelin, resistance training, nutritional supplementation, and stopping smoking have been recommended, the number of potential therapies is limited. ${ }^{5}$

Helicobacter pylori is a Gram-negative bacillus that causes many disorders of the upper gastrointestinal tract and has recently been associated with various nongastrointestinal disorders. ${ }^{6,7}$ Recent research has focused on whether $H$. pylori eradication is associated with metabolic changes. H. pylori eradication has been reported to increase 
the gastric secretion of ghrelin, which plays a critical role in various physiological processes by stimulating growth hormone secretion and regulating energy homeostasis. ${ }^{8-10}$ Ghrelin has been proposed as a treatment for sarcopenia because it can increase muscle mass by increasing food intake, activating the growth hormone-insulin-like growth factor axis, promoting myocyte differentiation and fusion, and inhibiting the production of anorectic proinflammatory cytokines. ${ }^{5,10}$ We hypothesized that $H$. pylori eradication might improve or prevent sarcopenia by increasing the plasma ghrelin concentration. The aim of this study was to examine whether $H$. pylori eradication is associated with the risk of low skeletal muscle mass, which is an integral component of sarcopenia.

\section{Methods}

\section{Study population}

We conducted a cross-sectional study of women who had routine health screening examinations at the Center for Health Promotion of Seoul St Mary's Hospital (Seocho-Gu, Seoul, South Korea) between March 2009 and July 2014. The inclusion criteria were women who 1) professed to be healthy on a questionnaire; 2 ) were aged $\geq 60$ years; and 3 ) could provide information regarding previous $H$. pylori-eradicating therapy and results for $H$. pylori IgG testing. Only those $\geq 60$ years were included, as sarcopenia mainly affects the elderly, and the expected prevalence in those under 60 were expected to be too low to draw statistical conclusions.

We excluded subjects who 1) did not have information regarding prior $H$. pylori-eradicating treatment; 2) were seronegative for $H$. pylori IgG and had no prior history of $H$. pylori-eradicating treatment because they were considered naïve to $H$. pylori infection; 3 ) had abnormal results on their health screening examination such as thyroid disorders, malignancies, chronic obstructive pulmonary disorders, heart failure, liver cirrhosis, or end-stage renal disease; 4) had a history of thyroid disease; 5) had a history of malignancy; 6) had undergone previous gastrointestinal surgery with the exception of appendectomy; 7) were heavy drinkers (>30.0 g alcohol/d); 8) were not ethnic Koreans; or 9) had missing records. This study used records that were approved by the Institutional Review Board of Seoul St. Mary's Hospital which waived the requirement for informed consent as this was a retrospective study using blinded records.

The subjects were divided into two groups: 1) those who were $H$. pylori IgG seropositive and had not received H. pylori-eradicating treatment; and 2) those who had received $H$. pylori-eradicating treatment.

\section{Data collection - demographic data, anthropometric measurements, and body composition}

All subjects completed a standardized, self-validated questionnaire during the routine health screening program. The questionnaire asked about smoking, alcohol consumption, exercise, and medical history of prior malignancy, surgery, diabetes, hypertension, dyslipidemia, thyroid disorders, cardiovascular and cerebrovascular diseases, and chronic obstructive pulmonary diseases. Medication history included whether the subject had received $H$. pylori-eradicating therapy and whether she is a current or regular user of aspirin, nonsteroidal anti-inflammatory drugs, antidiabetic medication, antihypertensive medication, or medication for dyslipidemia. Anthropometric measurements including weight, height, waist circumference, and blood pressure (BP) were measured by trained medical personnel. Waist circumference was measured in the horizontal plane at the midpoint of the distance between the lowest rib and the iliac crest. BP was measured in the right arm using a mercury sphygmomanometer with an adequate cuff size, with the subject in a seated position after at least 10 minutes of rest. Body mass index (BMI) was calculated as weight in kilograms divided by the square of height in meters $\left(\mathrm{kg} / \mathrm{m}^{2}\right)$. Body composition was analyzed by bioelectrical impedance analysis (BIA) using multifrequency BIA (Inbody 4.0; Biospace Co., Gangnam-Gu, Seoul, South Korea), according to previously established methods. ${ }^{11}$

\section{Data collection - blood samples}

Venous blood samples were taken in the morning after an overnight fast of at least 12 hours. Fasting plasma glucose, glycated hemoglobin, total cholesterol, triglyceride, high-density lipoprotein cholesterol (HDL-C), and low-density lipoprotein cholesterol (LDL-C) levels were measured on the Hitachi 7150 Autoanalyzer (Hitachi Ltd., Tokyo, Japan). Serum albumin, total protein, and creatinine concentrations were measured on the Hitachi 7600 Autoanalyzer (Hitachi Ltd.). Complete blood cell counts were performed using a Sysmex XE-2100 analyzer (Sysmex, Kobe, Japan). Serum pepsinogen I and II concentrations were measured using a latex-enhanced turbidimetric immunoassay (HBI Co., Anyang, South Korea). H. pylori IgG (Enzygnost $^{\circledR}$, Dade Behring, Marburg, Germany) testing was performed on all subjects.

\section{Definitions}

Low muscle mass measured by BIA was defined according to the Sarcopenia in Asia consensus report as 2 standard deviations (SDs) below the mean muscle mass of healthy 
women aged 20-39 years who had participated in the same health screening program. ${ }^{2}$ Subjects were considered $H$. pylori seropositive (H. pylori $\mathrm{IgG}^{+}$) if they had an H. pylori $\mathrm{IgG}$ concentration $>10.0 \mathrm{U} / \mathrm{mL}$. Obesity was defined according to the Korean Society for the Study of Obesity and World Health Organization Regional Office for the Western Pacific Region criteria $\left(\mathrm{BMI}>25 \mathrm{~kg} \mathrm{~m}^{2}\right){ }^{12}$ Type 2 diabetes was defined as $\mathrm{HbA}_{1 \mathrm{c}}$ level $\geq 6.5 \%$, previous type 2 diabetes diagnosis, or current antidiabetic therapy. The metabolic syndrome was defined according to the definitions of the American Heart Association and the National Heart, Lung, and Blood Institute, and the International Diabetes Federation as $\geq 3$ of the following: 1) waist circumference $\geq 80 \mathrm{~cm}$ in women, the modified criteria for the Asian population; 2) triglyceride concentration $\geq 150 \mathrm{mg} / \mathrm{dL}$ or use of triglyceride-lowering medication; 3) low HDL-C concentration ( $<50 \mathrm{mg} / \mathrm{dL})$; 4) systolic $\mathrm{BP} \geq 130 \mathrm{mmHg}$, diastolic $\mathrm{BP} \geq 85 \mathrm{mmHg}$, or use of antihypertensive medication; or 5) fasting glucose level $\geq 100 \mathrm{mg} / \mathrm{dL}$ or use of antidiabetic medication or previously diagnosed type 2 diabetes. ${ }^{13}$ Regular exercise was defined as moderate physical activity $\geq 30 \mathrm{~min} / \mathrm{d}$ on $>5 \mathrm{~d} / \mathrm{wk}$ and/or strenuous physical activity for $\geq 20 \mathrm{~min} / \mathrm{d}$ on $>3 \mathrm{~d} / \mathrm{wk}$. Alcohol consumption was categorized as either nondrinker or mild-to-moderate drinker (1.0-30.0 g alcohol/d). Smoking was classified as "yes" for those who had smoked $\geq 100$ cigarettes and "no" for those who had smoked $<100$ cigarettes during their lifetime.

\section{Statistical analysis}

Categorical variables were examined by Pearson's Chisquared test, and differences in continuous variables between the two groups were analyzed by the Student's $t$-test. A linear regression analysis for body muscle percentage was performed using risk factors associated with low muscle mass as continuous variables. Multivariable analysis of the risk factors for low muscle mass was performed using logistic regression. Odds ratios (ORs) and 95\% confidence intervals (CIs) were calculated for each variable in the multivariable analysis. Multicollinearity was determined for all multiple regression variables by calculating the tolerance and variance inflation factors. Any variable with a variance inflation factor $>5$ was excluded because of significant multicollinearity. All tests were two-sided and performed at the $5 \%$ level of significance using SAS software (SAS Institute, Cary, NC, USA).

\section{Results}

There were 6,230 asymptomatic healthy women aged $\geq 60$ years who participated in routine health screening examinations at the Center for Health Promotion of Seoul St Mary's Hospital between March 2009 and July 2014. Of these subjects, 5,169 were excluded from our study for the following reasons: 3,858 did not have information regarding H. pylori treatment, 518 were $H$. pylori $\mathrm{IgG}^{-}$and had not received $H$. pylori-eradicating treatment, 216 had abnormal health examination results, 272 had thyroid diseases, 122 had a history of malignancy, 8 had prior gastrointestinal surgery, 30 were heavy drinkers, 25 were foreign nationals, and 120 had missing records (Figure 1).

The body muscle mass of these subjects was compared with that of 7,906 women from the same routine health
5,169 excluded

- 3,858 no information on Helicobacter pylori treatment

$-518 H$. pylori $\lg G(-)$ and no previous treatment

-216 abnormal results

-272 thyroid diseases

-122 malignancies

-8 previous gastrointestinal operations

-30 heavy drinkers

-25 foreigners

-120 missing records

Figure I Flow chart of the study design. 
examinations, who were aged 20-39 years. The mean body muscle mass of the 20-39-year-old female population was $38.6 \%$ (SD, 3.1\%). According to the low muscle mass criteria, subjects with a body muscle mass $<2$ SD $(<32.4 \%)$ of the value in the 20-39-year-old group were classified as having low muscle mass.

Among the study population, 372 women had received H. pylori-eradicating therapy, and 689 were H. pylori $\mathrm{IgG}^{+}$ and had not received $H$. pylori-eradicating therapy. Subjects with $H$. pylori eradication had a significantly lower BMI (23.4 \pm 2.8 vs $\left.23.9 \pm 3.1 \mathrm{~kg} / \mathrm{m}^{2}, P=0.016\right)$ and percentage of low muscle mass $(13.7 \%$ vs $21.6 \%, P=0.002)$ and a significantly higher body muscle mass percentage $(35.5 \% \pm 3.0 \%$ vs $34.9 \% \pm 3.2 \%, P=0.006)$. Body fat percentage $(33.6 \% \pm 5.5 \%$ vs $34.4 \% \pm 6.1 \%, P=0.025)$, waist circumference, serum concentrations of total cholesterol, LDL-C, and albumin were significantly higher in the noneradicating group, whereas the pepsinogen I/II ratio and percentage of subjects who exercised regularly were significantly higher in the H. Pylori eradication group. Other clinical and demographic characteristics are shown in Table 1.

Univariable analysis was performed to identify the factors associated with low muscle mass. Age, white blood cell (WBC) count, serum triglyceride concentration, fasting glucose concentration, $\mathrm{HbA}_{1 \mathrm{c}}$ level, and the presence of hypertension or the metabolic syndrome were identified as risk factors for sarcopenia. The significant protective factors were HDL-C concentration, blood urea nitrogen concentration, having received $H$. pylori-eradicating therapy, and performing regular exercise. Regular exercise lessened the risk of low muscle mass by $43 \%$ (OR: $0.570,95 \% \mathrm{CI}$ : 0.413-0.788, $P=0.001$ ), and $H$. pylori-eradicating treatment lessened it by $42.4 \%$ (OR: $0.576,95 \%$ CI: $0.407-0.814$, $P=0.002$ ) (Table 2).

Table I Clinicodemographic characteristics of the study population

\begin{tabular}{|c|c|c|c|}
\hline & $\begin{array}{l}\text { Did not receive Helicobacter pylori } \\
\text { eradication treatment }(n=689)\end{array}$ & $\begin{array}{l}\text { Received Helicobacter pylori } \\
\text { eradication treatment }(n=372)\end{array}$ & $P$-value \\
\hline Age (years) & $66.6 \pm 5.2$ & $66.1 \pm 4.6$ & 0.094 \\
\hline Low muscle mass ( $\mathrm{n}, \%)$ & $149(21.6 \%)$ & $5 \mathrm{I}(13.7 \%)$ & 0.002 \\
\hline Body mass index $\left(\mathrm{kg} / \mathrm{m}^{2}\right)$ & $23.9 \pm 3.1$ & $23.4 \pm 2.8$ & 0.016 \\
\hline Body muscle percentage (\%) & $34.9 \pm 3.2$ & $35.5 \pm 3.0$ & 0.006 \\
\hline Body fat percentage (\%) & $34.4 \pm 6.1$ & $33.6 \pm 5.5$ & 0.025 \\
\hline Obesity (n, \%) & $22 I(32.1 \%)$ & $89(23.9 \%)$ & 0.005 \\
\hline Sarcopenic obesity (n, \%) & $107(15.5 \%)$ & $39(10.5 \%)$ & 0.023 \\
\hline Waist circumference $(\mathrm{cm})$ & $87.1 \pm 8.6$ & $85.8 \pm 8.3$ & 0.026 \\
\hline Diabetes (n, \%) & $103(14.9 \%)$ & $63(16.9 \%)$ & 0.395 \\
\hline Hypertension (n, \%) & $267(38.8 \%)$ & 144 (38.7\%) & 0.989 \\
\hline Metabolic syndrome (n, \%) & $324(47.0 \%)$ & 176 (47.3\%) & 0.929 \\
\hline Number of metabolic syndrome components & $2.4 \pm 1.2$ & $2.4 \pm 1.3$ & 0.289 \\
\hline Exercise (n, \%) & $467(67.8 \%)$ & $295(79.3 \%)$ & $<0.001$ \\
\hline Alcohol (n, \%) & $109(15.8 \%)$ & $55(14.8 \%)$ & 0.656 \\
\hline Smoking (n, \%) & $22(3.2 \%)$ & $12(3.2 \%)$ & 0.977 \\
\hline H. pylori seropositivity (n, \%) & $689(100 \%)$ & I 44 (38.7\%) & $<0.001$ \\
\hline Pepsinogen I (ng/mL) & $62.0 \pm 30.1$ & $53.2 \pm 27.8$ & 0.168 \\
\hline Pepsinogen II (ng/mL) & $20.3 \pm 11.3$ & $\mathrm{II} . \mathrm{I} \pm 8.7$ & $<0.00$ I \\
\hline Pepsinogen I/II ratio & $3.5 \pm 1.8$ & $5.8 \pm 2.2$ & $<0.00$ I \\
\hline White blood cell count $\left(\times 10^{6} / \mathrm{L}\right)$ & $5,330 \pm I, 430$ & $5,170 \pm 1,480$ & 0.094 \\
\hline Hemoglobin (g/dL) & $13.3 \pm 1.0$ & $13.4 \pm 1.0$ & 0.328 \\
\hline Platelet count $\left(\times 10^{9} / \mathrm{L}\right)$ & $238.6 \pm 54.0$ & $232.3 \pm 51.2$ & 0.062 \\
\hline Total cholesterol (mg/dL) & $201.6 \pm 37.9$ & $196.7 \pm 34.8$ & 0.037 \\
\hline Triglyceride (mg/dL) & $107.8 \pm 7 \mid .5$ & $109.2 \pm 76.3$ & 0.777 \\
\hline High-density lipoprotein (mg/dL) & $53.0 \pm 12.1$ & $54.5 \pm 12.3$ & 0.064 \\
\hline Low-density lipoprotein (mg/dL) & $121.6 \pm 34.4$ & || $6 .| \pm 3| .6$ & 0.011 \\
\hline Serum total protein $(\mathrm{g} / \mathrm{dL})$ & $7.2 \pm 0.4$ & $7.1 \pm 0.4$ & 0.067 \\
\hline Albumin (g/dL) & $4.3 \pm 0.3$ & $4.3 \pm 0.2$ & 0.041 \\
\hline Fasting glucose $(\mathrm{mg} / \mathrm{dL})$ & $99.9 \pm 17.6$ & $101.1 \pm 18.0$ & 0.292 \\
\hline Hemoglobin $A_{l c}(\%)$ & $5.8 \pm 0.6$ & $5.8 \pm 0.7$ & 0.112 \\
\hline Blood urea nitrogen $(\mathrm{mg} / \mathrm{dL})$ & $\mid 4.2 \pm 4.2$ & $14.6 \pm 3.8$ & 0.163 \\
\hline Creatinine (mg/dL) & $0.7 \pm 0.2$ & $0.7 \pm 0.1$ & 0.267 \\
\hline
\end{tabular}

Note: Data are presented as mean \pm standard deviation or in proportions. 
Table 2 Univariable analysis of low muscle mass risk factors

\begin{tabular}{|c|c|c|c|}
\hline & OR & $95 \% \mathrm{Cl}$ & $P$-value \\
\hline Age & 1.071 & $1.04 I-1.103$ & $<0.001$ \\
\hline Diabetes & 1.518 & $1.026-2.247$ & 0.037 \\
\hline Hypertension & 2.582 & $1.887-3.534$ & $<0.001$ \\
\hline Metabolic syndrome & 2.531 & $1.836-3.490$ & $<0.001$ \\
\hline $\begin{array}{l}\text { Number of metabolic syndrome } \\
\text { components }\end{array}$ & 1.548 & $1.358-1.764$ & $<0.001$ \\
\hline Exercise & 0.570 & $0.413-0.788$ & 0.001 \\
\hline Alcohol & 0.702 & $0.442-1.116$ & 0.135 \\
\hline H. pylori eradication treatment & 0.576 & $0.407-0.814$ & 0.002 \\
\hline White blood cell count & 1.279 & $1.156-1.414$ & $<0.001$ \\
\hline Total cholesterol & 1.003 & $0.999-1.007$ & 0.209 \\
\hline Triglyceride & 1.002 & $1.001-1.004$ & 0.013 \\
\hline High-density lipoprotein & 0.981 & $0.968-0.994$ & 0.005 \\
\hline Low-density lipoprotein & 1.004 & $0.999-1.008$ & 0.104 \\
\hline Serum total protein & 1.864 & $|.272-2.73|$ & 0.001 \\
\hline Albumin & 0.821 & $0.449-1.500$ & 0.521 \\
\hline Fasting glucose & 1.010 & $1.002-1.018$ & 0.012 \\
\hline $\mathrm{HbA}_{\mathrm{Ic}}$ & 1.410 & $1.123-1.770$ & 0.003 \\
\hline Blood urea nitrogen & 0.948 & $0.910-0.988$ & 0.011 \\
\hline Creatinine & 0.489 & $0.138-1.737$ & 0.269 \\
\hline
\end{tabular}

Abbreviations: $H$. pylori, Helicobacter pylori; $\mathrm{Cl}$, confidence interval; $\mathrm{OR}$, odds ratio.

A linear regression analysis of body muscle percentage was performed to identify significant predictors related to body muscle percentage among several continuous variables. Age, number of metabolic syndrome components, WBC count, and total serum protein were negatively correlated with body muscle percentage $(\beta=-0.109$ and $P<0.001$; $\beta=-0.260$ and $P<0.001, \beta=-0.110$ and $P<0.001 ; \beta=-0.077$ and $P=0.001$, respectively), while blood urea nitrogen concentration was positively associated with body muscle percentage $(\beta=0.120$ and $P<0.001)$.

Multivariable analysis to identify the risk factors for low muscle mass showed that age, WBC count, serum total protein concentration, and the presence of the metabolic syndrome were significant risk factors for sarcopenia. H. pylori-eradicating therapy (OR: $0.632,95 \% \mathrm{CI}: 0.440$ 0.824, $P=0.013$ ) was a significant preventive factor, but regular exercise (OR: $0.710,95 \%$ CI: $0.504-1.002, P=0.051$ ) was not significant (Table 3).

Table 3 Multivariable analysis of low muscle mass risk factors

\begin{tabular}{llll}
\hline & OR & 95\% CI & P-value \\
\hline Age & 1.064 & $\mathrm{I} .031-1.097$ & $<0.00 \mathrm{I}$ \\
Metabolic syndrome & $2.01 \mathrm{I}$ & $\mathrm{I} .432-2.824$ & $<0.00 \mathrm{I}$ \\
Exercise & 0.710 & $0.504-\mathrm{I} .002$ & $0.05 \mathrm{I}$ \\
H. pylori eradication treatment & 0.632 & $0.440-0.824$ & 0.013 \\
White blood cell count & $\mathrm{I} .179$ & $\mathrm{I} .057-\mathrm{I} .3 \mathrm{I} 5$ & 0.003 \\
Serum total protein & $\mathrm{I} .593$ & $\mathrm{I} .063-2.388$ & 0.024 \\
Blood urea nitrogen & $0.93 \mathrm{I}$ & $0.893-0.970$ & $0.00 \mathrm{I}$ \\
\hline
\end{tabular}

Abbreviations: $H$. pylori, Helicobacter pylori; $\mathrm{Cl}$, confidence interval; $\mathrm{OR}$, odds ratio.

\section{Discussion}

We investigated whether $H$. pylori-eradicating treatment could improve the low muscle mass status in elderly women aged $\geq 60$ years. We found that elderly women with prior H. pylori eradication had a reduced risk of low muscle mass. The prevalence of low muscle mass was $13.7 \%$ in subjects with a history of $H$. pylori eradication compared with $21.6 \%$ in those without this history. In our study, prior $H$. pylori-eradicating treatment reduced the risk of low muscle mass by $37 \%$.

Sarcopenia is a complex entity of clinical importance because of its association with adverse outcomes such as functional impairment, cardiovascular disease, metabolic disorders, falls, poorer quality of life, and mortality. ${ }^{14}$ Studies have suggested that multiple risk factors such as physical inactivity, multimorbidity, cigarette smoking, insulin resistance, changing hormone function, and nutritional deficiencies may all contribute to sarcopenia. ${ }^{2-4}$

Our study identified H. pylori infection as a risk factor for low muscle mass. Although the reason for this is unknown, we speculate that ghrelin and systemic inflammation may be involved. H. pylori infection reduces, whereas $H$. pylori eradication increases the circulating ghrelin concentration. ${ }^{9,15-17}$ Ghrelin is a gut hormone with key functions in nutrient sensing, meal initiation, and appetite and may also counteract against skeletal muscle loss. ${ }^{10,18}$ Studies have reported that H. pylori eradication increased serum ghrelin levels and caused weight gain. ${ }^{8} 9$ Long-term follow up of H. pyloriinfected children found that $H$. pylori eradication was associated with an increase in both serum ghrelin level and lean body mass. ${ }^{19}$ This supports our hypothesis that $H$. pylorieradicating therapy may improve body composition. Another study found that lean body mass increased significantly without any increase in body fat after $H$. pylori eradication, which also supports our hypothesis. ${ }^{20}$ Further studies should investigate whether $H$. pylori eradication improves both appendicular muscle mass and strength.

Another possible mechanism is the systemic inflammation caused by H. pylori infection. ${ }^{21}$ H. pylori-associated systemic inflammation increases the levels of proinflammatory cytokines such as tumor necrosis factor- $\alpha$ and interleukin- 6 , which promote muscle wasting. ${ }^{22,23} \mathrm{H}$. pylori eradication reduces or normalizes the levels of such cytokines. ${ }^{23-26}$ This may help explain the lower prevalence of sarcopenia in the H. pylorieradication group in our study. This is further corroborated by a study in which parkinsonism-associated cachexia improved after H. pylori eradication in patients for whom the treatment was successful compared with those for whom the treatment failed. ${ }^{27}$ 
Our study has inherent limitations in that this was a retrospective, cross-sectional study. The $H$. pylori treatment of these subjects was reported by a self-administered questionnaire, which limited the data that could be collected about the timing, duration, and success of $H$. pylori eradication. However, there were significantly higher $H$. pylori IgG levels and pepsinogen I/II ratio in the $H$. pylori-eradicated group, which supported H. pylori eradication. ${ }^{28}$ Another important limitation is the use of BIA in assessing skeletal muscle mass. Current recommendations suggest the use of dual X-ray energy absorptiometry to measure body composition as well as measuring muscle strength and function in diagnosing sarcopenia. ${ }^{3}$ However, the reasonable cost, noninvasiveness, lack of radiation exposure, and convenient use have made BIA suitable for community sarcopenia assessment, which somewhat mitigates this limitation. ${ }^{2}$

The risk factors for low muscle mass in this study were age, high WBC count, reduced serum total protein concentration, and the presence of the metabolic syndrome. A high WBC count has been reported to correlate with interleukin-6 level, ${ }^{29}$ which is associated with both systemic inflammation and muscle wasting. ${ }^{4}$ The metabolic syndrome reflects insulin resistance and is associated with reduced protein synthesis in aged muscle. ${ }^{30}$ Exercise showed a tendency to act as a preventive factor for sarcopenia, which has been noted before. . $^{5,31}$ $H$. pylori treatment was more effective than exercise in reducing the risk of low muscle mass. Considering that not all patients would have achieved complete $H$. pylori eradication, the potential of $H$. pylori eradication as a treatment for sarcopenia becomes even more significant.

Sarcopenia is a clinically significant, intricate entity with limited treatment options. Our study showed a positive association between $H$. pylori-eradicating therapy and a reduced risk of low muscle mass. This finding should be confirmed in prospective longitudinal studies to determine the long-term effects of $H$. pylori eradication on sarcopenia.

\section{Disclosure}

This research was supported by the program of Global Research and Development Center through the National Research Foundation of Korea, funded by the Ministry of Science, ICT and Future Planning (NRF-2011-0031644). The authors report no other conflicts of interest in this work.

\section{References}

1. Rosenberg IH. Sarcopenia: origins and clinical relevance. J Nutr. 1997;127(Suppl 5):990s-991s.

2. Chen LK, Liu LK, Woo J, et al. Sarcopenia in Asia: consensus report of the Asian Working Group for Sarcopenia. J Am Med Dir Assoc. 2014; 15(2):95-101.
3. Cruz-Jentoft AJ, Baeyens JP, Bauer JM, et al. Sarcopenia: European consensus on definition and diagnosis: report of the European Working Group on Sarcopenia in Older People. Age Ageing. 2010;39(4): 412-423.

4. Walrand S, Guillet C, Salles J, Cano N, Boirie Y. Physiopathological mechanism of sarcopenia. Clin Geriatr Med. 2011;27(3): 365-385.

5. Wakabayashi H, Sakuma K. Comprehensive approach to sarcopenia treatment. Curr Clin Pharmacol. 2014;9(2):171-180.

6. Franceschi F, Zuccala G, Roccarina D, Gasbarrini A. Clinical effects of Helicobacter pylori outside the stomach. Nat Rev Gastroenterol Hepatol. 2014;11(4):234-242.

7. Malfertheiner P, Selgrad M. Helicobacter pylori infection and current clinical areas of contention. Curr Opin Gastroenterol. 2010;26(6): 618-623.

8. Lender N, Talley NJ, Enck P, et al. Review article: associations between Helicobacter pylori and obesity - an ecological study. Aliment Pharmacol Ther. 2014;40(1):24-31.

9. Nweneka CV, Prentice AM. Helicobacter pylori infection and circulating ghrelin levels - a systematic review. BMC Gastroenterol. 2011;11:7.

10. Pradhan G, Samson SL, Sun Y. Ghrelin: much more than a hunger hormone. Curr Opin Clin Nutr Metab Care. 2013;16(6):619-624.

11. Kim H, Kim CH, Kim DW, et al. External cross-validation of bioelectrical impedance analysis for the assessment of body composition in Korean adults. Nutr Res Pract. 2011;5(3):246-252.

12. Oh SW. Obesity and metabolic syndrome in Korea. Diabetes Metab J. 2011;35(6):561-566

13. Alberti KG, Eckel RH, Grundy SM, et al. Harmonizing the metabolic syndrome: a joint interim statement of the International Diabetes Federation Task Force on Epidemiology and Prevention; National Heart, Lung, and Blood Institute; American Heart Association; World Heart Federation; International Atherosclerosis Society; and International Association for the Study of Obesity. Circulation. 2009;120(16): 1640-1645.

14. Perna S, Guido D, Grassi M, Rondanelli M. Association between muscle mass and adipo-metabolic profile: a cross-sectional study in older subjects. Clin Interv Aging. 2015;10:499-504.

15. Yang YJ, Sheu BS, Yang HB, Lu CC, Chuang CC. Eradication of Helicobacter pylori increases childhood growth and serum acylated ghrelin levels. World J Gastroenterol. 2012;18(21):2674-2681.

16. Ulasoglu C, Isbilen B, Doganay L, Ozen F, Kiziltas S, Tuncer I. Effect of Helicobacter pylori eradication on serum ghrelin and obestatin levels. World J Gastroenterol. 2013;19(15):2388-2394.

17. Boltin D, Niv Y. Ghrelin, Helicobacter pylori and body mass: is there an association? Isr Med Assoc J. 2012;14(2):130-132.

18. Tai K, Visvanathan R, Hammond AJ, Wishart JM, Horowitz M, Chapman IM. Fasting ghrelin is related to skeletal muscle mass in healthy adults. Eur J Nutr. 2009;48(3):176-183.

19. Pacifico L, Anania C, Osborn JF, et al. Long-term effects of Helicobacter pylori eradication on circulating ghrelin and leptin concentrations and body composition in prepubertal children. Eur J Endocrinol. 2008;158(3):323-332.

20. Kebapcilar L, Sari I, Renkal AH, et al. The influence of Helicobacter pylori eradication on leptin, soluble CD40 ligand, oxidative stress and body composition in patients with peptic ulcer disease. Intern Med. 2009;48(24):2055-2059.

21. Jackson L, Britton J, Lewis SA, et al. A population-based epidemiologic study of Helicobacter pylori infection and its association with systemic inflammation. Helicobacter. 2009;14(5):108-113.

22. Figura N, Palazzuoli A, Vaira D, et al. Cross-sectional study: CagApositive Helicobacter pylori infection, acute coronary artery disease and systemic levels of B-type natriuretic peptide. J Clin Pathol. 2014;67(3):251-257.

23. Consolazio A, Borgia MC, Ferro D, et al. Increased thrombin generation and circulating levels of tumour necrosis factor-alpha in patients with chronic Helicobacter pylori-positive gastritis. Aliment Pharmacol Ther. 2004;20(3):289-294. 
24. Ando T, Kusugami K, Ohsuga M, et al. Differential normalization of mucosal interleukin-8 and interleukin-6 activity after Helicobacter pylori eradication. Infect Immun. 1998;66(10):4742-4747.

25. Jang EJ, Park SW, Park JS, et al. The influence of the eradication of Helicobacter pylori on gastric ghrelin, appetite, and body mass index in patients with peptic ulcer disease. J Gastroenterol Hepatol. 2008; 23(Suppl 2):S278-S285.

26. Nakagawa H, Tamura T, Mitsuda Y, et al. Significant association between serum interleukin-6 and Helicobacter pylori antibody levels among H. pylori-positive Japanese adults. Mediators Inflamm. 2013; 2013:142358.

27. Dobbs RJ, Dobbs SM, Weller C, et al. Role of chronic infection and inflammation in the gastrointestinal tract in the etiology and pathogenesis of idiopathic parkinsonism. Part 1: eradication of Helicobacter in the cachexia of idiopathic parkinsonism. Helicobacter. 2005;10(4): 267-275.
28. Pimanov SI, Makarenko EV, Voropaeva AV, Matveenko ME, Voropaev EV. Helicobacter pylori eradication improves gastric histology and decreases serum gastrin, pepsinogen I and pepsinogen II levels in patients with duodenal ulcer. J Gastroenterol Hepatol. 2008;23(11): 1666-1671.

29. Leng S, Xue QL, Huang Y, et al. Total and differential white blood cell counts and their associations with circulating interleukin-6 levels in community-dwelling older women. J Gerontol A Biol Sci Med Sci. 2005;60(2):195-199.

30. Volpi E, Mittendorfer B, Rasmussen BB, Wolfe RR. The response of muscle protein anabolism to combined hyperaminoacidemia and glucose-induced hyperinsulinemia is impaired in the elderly. $J$ Clin Endocrinol Metab. 2000;85(12):4481-4490.

31. Jones TE, Stephenson KW, King JG, Knight KR, Marshall TL, Scott WB. Sarcopenia - mechanisms and treatments. J Geriatr Phys Ther. 2009;32(2):83-89.
Clinical Interventions in Aging

\section{Publish your work in this journal}

Clinical Interventions in Aging is an international, peer-reviewed journal focusing on evidence-based reports on the value or lack thereof of treatments intended to prevent or delay the onset of maladaptive correlates of aging in human beings. This journal is indexed on PubMed Central, MedLine,

\section{Dovepress}

CAS, Scopus and the Elsevier Bibliographic databases. The manuscript management system is completely online and includes a very quick and fair peer-review system, which is all easy to use. Visit http://www.dovepress. $\mathrm{com} /$ testimonials.php to read real quotes from published authors. 